\title{
IT Governance for the University of Cuenca
}

\author{
Rodrigo Padilla-Verdugo, Master in Information Management ${ }^{1}$, Víctor Saquicela-Galarza, PhD in Computer Science \\ and Artificial Intelligence ${ }^{2}$ \\ ${ }^{1}$ Universidad de Cuenca, Ecuador, rodrigo.padilla@ucuenca.edu.ec \\ ${ }^{2}$ Universidad de Cuenca, Ecuador, victor.saquicela@ucuenca.edu.ec
}

\begin{abstract}
Information Technology Governance in Latin America is still in process. The University of Cuenca faces new challenges due to its institutional growth and the development of teaching and research, in which the institution as a whole does not obtain a significant contribution of information technologies. To solve this problem, the University of Cuenca proposes a Governance Model of Information Technologies based on Cobit's processes, which involve important changes in the role that technology plays in organizations, the prioritization of their strategies and governance components, the work model, governance and management structures, processes and corporate culture management.
\end{abstract}

Keywords-- IT Governance, Corporate Governance, IT Management, Digital Transformation.

\section{INTRODUCTION}

Information Technologies (IT) are transforming organizations by using new information systems, applications and technologies that help improve their performance, develop a competitive advantage, and even change business models. Information systems and technologies are important tools that enable companies to create new products and services, as well as new business models [1]. Investments in IT have increased significantly in organizations in recent years; according to Laudon [1] global investment in information technology has increased by thirty percent from 2005 to 2015 , representing approximately twenty percent of all capital investment in global organizations.

How to make that new information technologies and investments in this area truly add value to the organization? The answer to this question is certainly by implementing IT governance. Several tools have been developed for the implementation of an IT Governance: best practices, reference frameworks and standards such as COBIT [2], ISO/IEC 38500:2008 [3], VAL IT [4], among others.

In higher education institutions (IES by its acronym in Spanish) it is essential to have IT that would leverage the activities of teaching development, research, relationship with society and management of the institution. Universities require "efficient and effective management, which today must be based on the intelligent use of IT" [5]. In addition, it is very important to analyze any alternatives to transform higher education from the possibilities offered by new information technologies. According to Cordero [6] "it is necessary to have its own IT Governance Model for the university, which rescues or re-takes positive aspects of other experiences, best practices, frameworks of reference". IT governance is critical

Digital Object Identifier (DOI):

http://dx.doi.org/10.18687/LACCEI2020.1.1.312

ISBN: 978-958-52071-4-1 ISSN: 2414-6390 to the strategic and comprehensive use of information technologies for universities, making them an important driver of their development and sustainability [7].

Due to this reality and with the purpose of ensuring that IT at the University of Cuenca contributes with real value to the institution, the IT Governance model is proposed, which includes the definition of specific objectives based on an analysis of gaps and expectations by the university community. The components of governance and management, the operating model and the governance and management structures, as well as a restructuring of the functional organic and a balanced scorecard for IT.

In the following sections, there is a literature review on the existing studies in the universities of Ecuador and Latin America, subsequently, the problem to be solved and the context of the university are presented. The following section describes the proposed IT Governance Model and finally an analysis of the lessons learned; finally, the conclusions and future studies related to the topic are presented.

\section{RELATED STUDIES}

In this section, we present some background information related to the IT governance for the universities in the context of the Ecuadorian and Latin American universities.

\section{A) IT Governance in Ecuadorian Universities}

IT governance in Ecuadorian universities is at an early stage. This is confirmed by the UETIC 2018 study [8], in which 42 universities participated. According to this study, 5 out of 10 universities consider IT in their institutional planning, 5 out of 10 universities have IT policies approved, just 2 out of 10 have a comprehensive IT governance and management dashboard, 4 out of 10 universities have established governance and management processes, and only 3 out of 42 universities have an IT Committee. IT governance is the responsibility of the members of the Management Committee and the top executives of the organization. This means that it is not about managing the IT department or providing IT services to the organization [9], but of the direct participation of the authorities in defining the role of IT in the institution and in implementing an appropriate strategy to generate benefits for the institution. They should also facilitate the development of IT and control risks that may exist due to the inadequate operation of the technology.

The implementation of an IT governance in Ecuadorian universities is almost zero. There is the Amazon State University, a public university with around 4,000 students and 
180 professors, which has emerged with IT governance and management with institutional objectives with IT strategies and definition of strategic planning managers, decision-making and IT exploitation. For its part, Laica Eloy Alfaro University of Manabí has carried out an assessment on the capacity of the processes that contribute to the IT government, in which it is concluded that "it was determined that none of its processes are managed and established, i.e., its IT governance processes are at a level 0" [10]. From our knowledge there are no other recorded experiences regarding the implementation of IT governance in Ecuadorian universities. As can be seen, while IT governance is essential to ensure that IT generates value for university institutions, Ecuador's experience at universities is very limited.

It is important to consider that in order to contribute to the digital transformation in the IES of the country, it is necessary to continue with the strategies and incorporate those that ease the participation and adoption by university authorities in the field of IT governance and digital transformation [11].

\section{B) IT Governance in Latin American Universities}

IT governance in Latin American universities has developed at a slow pace; there is little evidence of IT governance implementation in universities showing their implementation and advancement.

In Mexico, the study "State of Information and Communications Technologies in The Mexican Higher Education Institutions Study 2018" was carried out published by the National Association of Universities and Higher Education Institutions (ANUIES). This study involving 144 associated IES states that "most IES in Mexico do not document or disseminate success stories in the implementation of good practices or lessons learned to share experiences. Moreover, they have not used yet as standard practice the comparison of good practices between universities, and they have not developed strategies to assess the maturity of ICT governance." [11].

There are other studies that have been developed in Latin America as well as projects, master's thesis and articles with no transcendence in the implementation of IT governance in universities. The implementation of the government of information technologies in universities of Colombia (PAGTI) presents a proposal based on the Spanish model GTI4U [12]. The master's thesis on governance and management framework for IT architecture in higher education institutions in Colombia proposes a model of IT governance and management and implements a case study at Universidad del Magdalena, where it is proposed as an objective level 4 in all processes [13]. In Peru, an Information Technology Governance Reference Model for University Institutions (GTIUP) is proposed, including three stages: 1) Improvement of IT governance processes, 2) improvement of management processes, and 3) improvement of IT governance and management processes, which is not implemented at any university [14]. The master's thesis on a government model proposal for information technology for Universidad Científica del Sur in Peru, is also based on the Spanish model GTI4U. Similar works have been presented in the editions of the TICAL Conference (The Directors of Information and Communications Technologies's Network).

The IT governance model for GTI4U universities developed by Antonio Fernández and Faraón Llorens is well cited in several cases of analysis and implementation in Latin America. This model includes three levels: Level 1 incorporates the principles, governance model and good practices based on ISO 38500; level 2 includes a maturity model (MM); and Level 3 contains IT governance indicators to measure whether IT governance best practices are being successfully conducted. The authors state that at the time the IT Sectoral Commission of the Conference of Rectors of the Spanish Universities (CRUE_TIC) has promoted the implementation of an IT governance system in several Spanish universities, the GTI4U model, developed specifically for the university field and fully aligned with the principles of ISO 38500 [15], has been used.

\section{PROBLEMS AND CONTEXT IN WHICH IT DEVELOPS}

The University of Cuenca is a public university, the second oldest in Ecuador, founded in 1857. It is located in the city of Cuenca and has six university campuses. Currently, the University of Cuenca has 49 careers in 12 Faculties and have more than 16 thousand students, 1120 professors and 544 employees. All of the careers are offered on campus and have no headquarters outside the city of Cuenca.

The University of Cuenca has an Office of Information and Communication Technologies (DTIC) that depends on the Rector's Office of the university and is responsible for the management, coordination and execution of projects in the field of information and communication, aimed at improving the academic and administrative quality of the institution.

Different technological changes have allowed the University of Cuenca to implement technological services and infrastructures that contribute to the development of university activities; however, the growth of the institution, the development of research and new institutional demands mean that new drawbacks and challenges have emerged that must be considered when implementing IT.

The biggest drawback is that there is a low level of IT contribution to the achievement of the institution's objectives. From a diagnosis made in 2019, five relevant aspects are observed: lack of integration between functional areas, there is no culture of collaboration in the staff, unnecessary complexity and rigidity of the technological infrastructure, difficulty in growth and innovation and functional silos in the organization, as well as complexity in business processes.

Currently, DTIC has an area of services that provides IT services through a catalog; however, it has not been updated since 2015. From the diagnosis made, it is observed that the 
maturity level of IT processes based on Cobit 2019 is that IT at the University of Cuenca "work", i.e., it is at Level 1; equipment and systems are managed and acceptable support services are provided, which can be improved.

\section{IT GOVERNANCE MODEL FOR THE UNIVERSITY OF CUENCA}

The proposal for the definition of the IT Governance Model for the University of Cuenca is described below. It starts with a diagnosis, it establishes the guidelines of governance and management, and it describes the model of governance and its components.

\section{A. General diagnosis}

For the implementation of the IT Governance Model, a diagnosis of governance, an IT management, and a gap analysis of IT processes were carried out with respect to the 2019 COBIT reference model. For the diagnosis, the following activities were performed: 1) IT context analysis workshop with the DTIC management team, this is with the DTIC Director and three area coordinators, 2) Raising perception of the current situation and key IT components with DTIC staff, 3) Raising perception of the current situation and key IT components with university authorities, 4) Open surveys to teachers, employees and students on the perception of IT services, 5) IT process assessment, 6) IT risk analysis with IT management team and other stakeholders, and 7) Current situation with analysis and future prospects with the university rector.

Based on the survey of perception and the evaluation of IT process capabilities conducted, it was observed that the level of IT contribution or maturity to the achievement of institutional objectives, both operational and strategic, is low. At the general level, a level 1 of maturity is reached according to the proposal of Cobit 2019 as seen in Figure 1; i.e., "IT works," it manages equipment and systems, and it provides acceptable support services, although it can be improved.

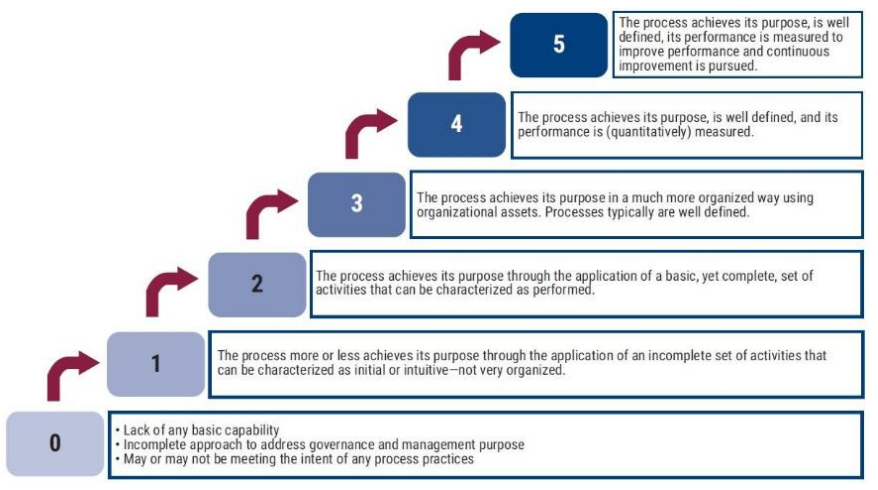

Fig. 1. Cobit 2019 Process capacity levels.
As mentioned in the previous section, there are several factors that demonstrate the low contribution level of IT to the university's objectives that were identified in this initial diagnosis and reflect the level of maturity mentioned.

\section{B) Guidelines for an IT Governance and Management Model}

The criticality of IT governance and management objectives was assessed for the development of the Governance and IT management objectives, the analysis of gaps between the present and the desired future was performed and the government components were prioritized.

Criticality assessment of governance and management objectives. As established by Cobit 2019, each of the forty IT governance and management processes are conducted to support the achievement of a specific goal. An important step is to identify the level of criticality of their related objectives, so that a plan for improvements can be developed, taking into account processes that support high criticality goals and that have gaps in their current and expected level of performance.

To analyze the level of criticality, 4 factors were taken into account: 1) the institution's strategy, 2) the strategic objectives, 3) risk identification and 4) the problems observed. These factors identified the level of importance of the different strategies proposed by Cobit 2019 and as a result, at a level of 1 to 5 , it was observed that the strategy of University of Cuenca is oriented towards innovation at level 5, customer service at a level 3, growth and cost leadership at level 1 . In this way, the university shows to have as a primary strategy the innovation/differentiation of its services and as a secondary strategy the stability of the customer service (teachers, students, society).

The institutional strategy is carried out by achieving a set of objectives, which are defined in the COBIT 2019 framework and are structured along the dimensions of the integral dashboard. The University of Cuenca pointed out as its key business objectives: 1) culture of customer-oriented service, 2) product and service innovation, 3) competitive product and service portfolio, and 4) compliance with external laws and regulations.

The risk profile identifies the type of IT-related risk to which the organization is exposed to, and it indicates critical risk areas. Of the 19 categories or risk areas listed by Cobit, 4 areas of very high risk were identified at the University of Cuenca: 1) unauthorized activities, 2) political and economic issues, 3) technology-based innovation, and 4) data and information management.

Finally, the IT-related issues facing the institution were assessed. Among these are: 1) frustration among the different IT areas due to the perception of a low contribution to the business value, 2) frustration between the business departments and the IT department due to failed initiatives or a perception of low contribution to the business value and 3) problems in service delivery by IT providers. 
With these four factors mentioned, 15 critical governance and IT management objectives were achieved and will guide the development of the later phases of the development of the IT Governance Model for the University of Cuenca. Figure 2 shows the 40 objectives proposed by Cobit 2019, of which 15 have a critical level, 16 important levels and 9 complementary levels.

Gap analysis. The gap analysis took into account the level of criticality of each objective, the suggested target level of capacity to be achieved, thus, obtaining the difference between the two elements.
15 critical objectives were selected and 4 targets with a higher gap were identified within the result of this analysis, as follows: 1) Managed Innovation, 2) Managed Knowledge, 3) Change Acceptance and Managed Transition and 4) Managed business architecture.

Prioritization of governance components. This section introduces the prioritization of the key components of the governance model to be implemented. Based on the problems observed, the perception of those involved and the expectations raised regarding the expected level of IT contribution, it was observed that the key governance

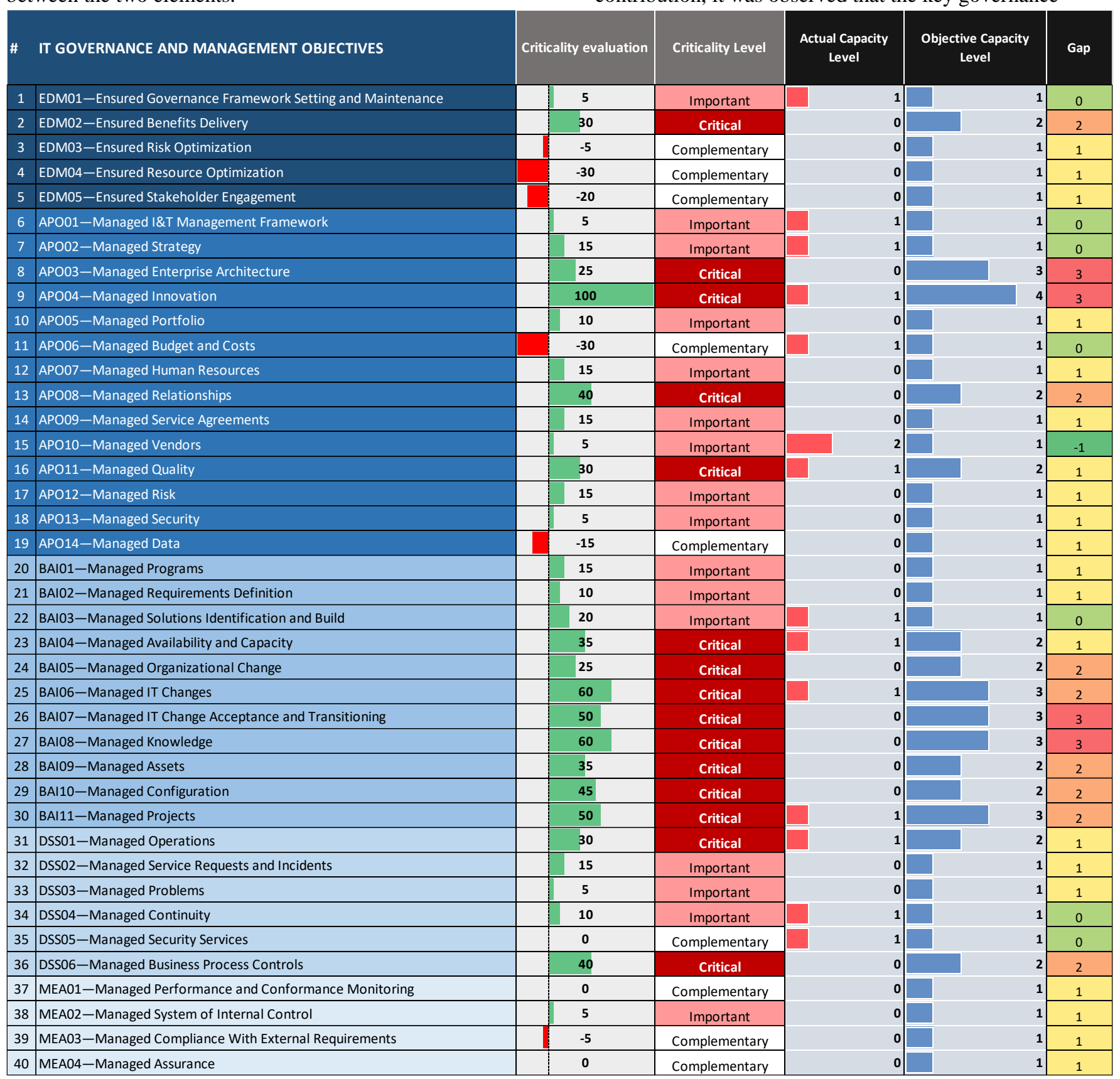

Fig. 2. Government objectives and IT management based on Cobit 2019 processes. 
components to be addressed are: 1) organizational structures, 2) IT processes, 3) people's culture, attitudes and behaviors.

\section{C) IT Governance Model}

The IT Governance Model includes the operating model, corporate culture management, governance structures, functional IT organizational structure, balanced scorecard and processes. Each of the components is described below.

IT operational model. The operational model of information technologies that are adopted as the basis for the definition of the IT governance model for the University of Cuenca is based on international recommendations and good practices, among which are: presenting a clear disaggregation between governance and management responsibilities (COBIT); identify the need to establish a demand control or business requirements, which can be met through the current offer service capacity of IT (GARTNER); ensure that the development and evolution of IT-provided solutions and services are governed by a strong enterprise architecture practice (TOGAF); apply a service management, quality and continuous improvement (ITIL) approach; manage independently the information security system and controls (ISO 27001). Figure 3 shows the operating model defined for University of Cuenca.

It is important to note that in the operating model is clearly observed the governance and management activities, which is the basis of Cobit's 2019 proposal. This aspect was applied in all definitions of organizational structures, processes, and other components that are part of the University of Cuenca's IT Governance Model.

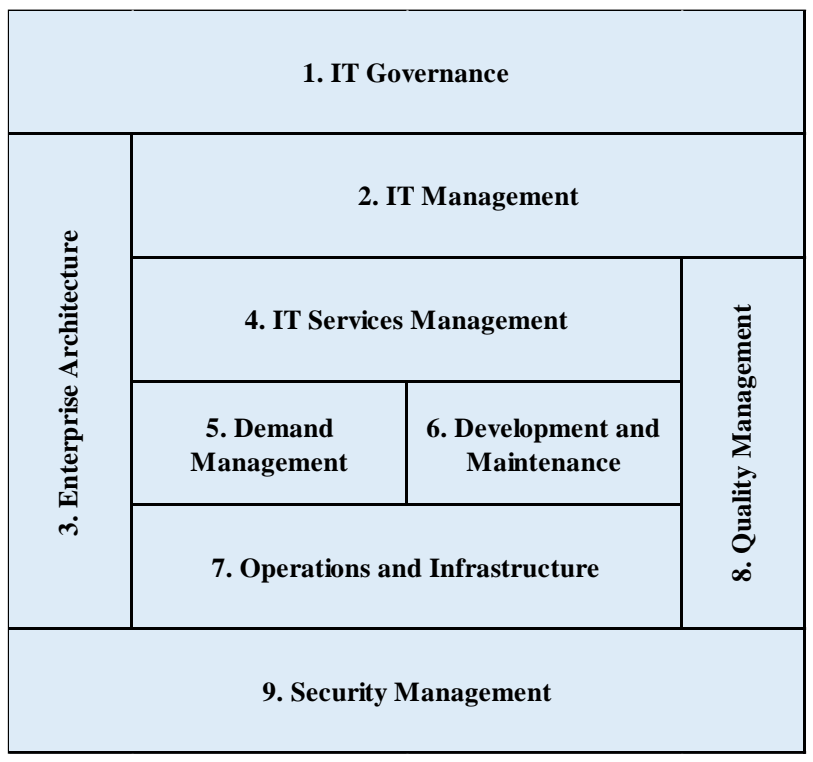

Fig. 3. IT operational model of University of Cuenca

Corporate culture management. Proper implementation and utilization of IT are only achieved with a good corporate culture. To this end, it was defined in the IT Governance Model for the University of Cuenca, the management of culture, attitudes and behaviors based on Franklin Covey's leadership model (The 7 Habits for Managers) and Thomas International's essential skills approach.

The model of the management of culture, attitudes and behaviors of the University of Cuenca is presented in Figure 4.

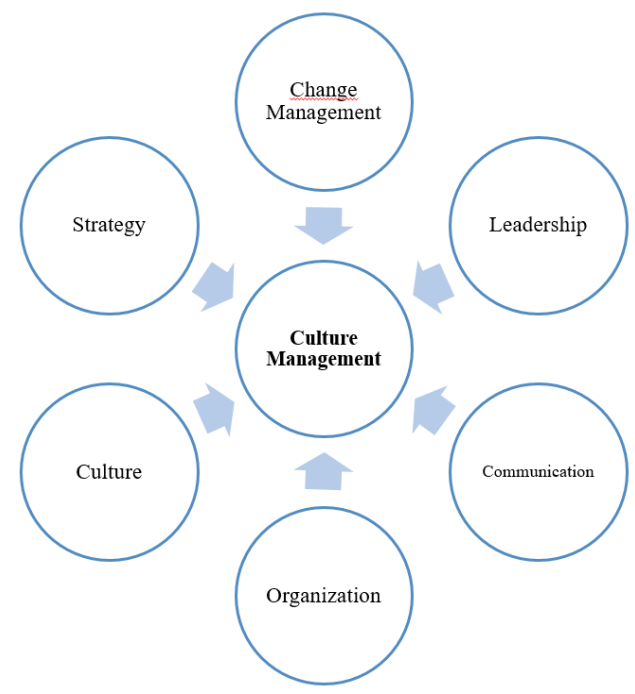

Fig. 4. University of Cuenca culture management model based on Franklin Covey's leadership model and Thomas International's essential skills approach.

This model includes six elements that are described below:

Change Management. It focuses on managing the aspects of change related to people, technology and organization.

Leadership. It includes a set of management skills or directives used to influence the way people are or act, which inspire the team by making people work effectively and committedly towards achieving the goals and objectives.

Communication. It allows the development of communication skills to ensure that messages are interpreted appropriately by the various stakeholders.

Organization. It orders the precise resources and functions to meet the organization's goals.

Organizational culture. It determines how the organization works by observing its strategies, structures and the system as a whole.

Organizational strategy. It enables the creation, implementation and evaluation of decisions within the organization, on the basis of which the long-term objectives will be achieved.

Governance structures. The definition of IT governance structures was based on the functional organic model of the University of Cuenca and the DTIC. Two IT governance structures were defined with their specific objectives, members and responsibilities; these structures are: 
Strategic IT Committee (CETI). This committee is responsible for approving the role of IT in the institution's strategies, selecting IT strategy, ensuring compliance with IT policies, monitoring the provision of IT resources, securing investments, and reviewing and controlling risks associated with IT. It is chaired by the rector or his delegate, and composed of two members of the University Council (the maximum governing body of the university) and two general directors.

IT Management Committee (CGTI). This committee is responsible for recommending CETI, the strategy, managing and monitoring IT, optimizing and measuring resource performance, planning and coordinating IT activities. This committee is chaired by the IT Director and consists of three coordinators and five managers of cross-cutting IT units.

Re-design of DTIC functional organic structure. In order to achieve an adequate implementation of the IT governance and management processes and achieve the objectives proposed by Cobit 2019 at the University of Cuenca, it was proposed to change the organic structure of the DTIC of University of Cuenca, considering new support units by reassigning functions to each of the components of its structure.
The new organic structure of DTIC is constituted on the basis of a matrix approach with vertical lines of responsibility (Coordinators) and horizontal support lines (Cross-sectional units). Support units report directly to the director of DTIC and their levels of authority and responsibility emanate from it. The support units have a unit manager and a working team. The projects faced by the DTIC will be implemented under a holistic approach, by multidisciplinary teams composed of people from the coordinators and support units.

Each coordination and support unit of the DTIC is assigned the responsibilities, which were carried out from the 40 Cobit objectives and which were assigned to each of the Coordination offices and Support units; it was necessary to map existing positions at University of Cuenca and the generic roles proposed by COBIT 2019. Figure 5 shows the new organic structure of the DTIC and the assigned Cobit processes.

IT Balanced scorecard. The definition of indicators and metrics is a key component in the IT governance and management model of the University of Cuenca to measure the efforts related to the processes proposed by the model, and in turn align them with the business goals of the organization.

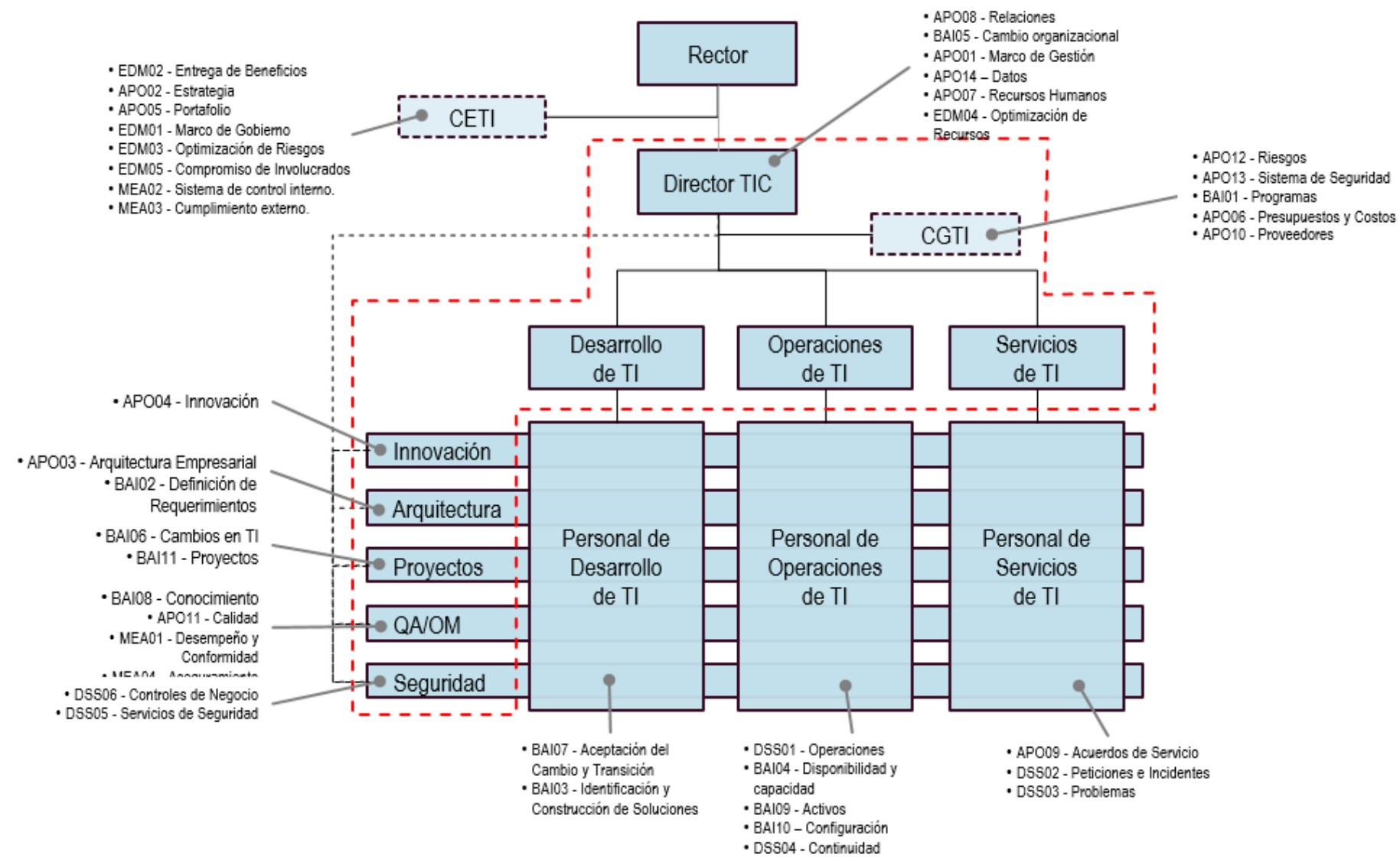

Fig. 5. Redesigned organic structure of University of Cuenca DTIC that includes government and management processes. 
For the construction of the indicator structure, the Balanced Scorecard (BSC) model was considered, which proposes management from four perspectives that allow comprehensive monitoring of the status of indicators, their goals and their impact in the organization. These 4 perspectives are financial, customer, internal and learning and growth.

Based on the analysis of the processes and organizational context, the indicators for each of the IT dashboard perspectives presented in Table 1 are defined.

TABLE 1.

UNIVERSITY OF CUENCA'S IT BALANCED SCORECARD

\begin{tabular}{|c|c|}
\hline FINANCIAL & CUSTOMER \\
\hline $\begin{array}{l}\text { Objective: Benefits obtained from } \\
\text { the portfolio of investments and } \\
\text { services enabled by IT. } \\
\text { Metrics: } \\
\text { - Successful projects. } \\
\text { - SLA compliance. }\end{array}$ & $\begin{array}{l}\text { Objective: Agility to turn business } \\
\text { requirements into operational } \\
\text { solutions. } \\
\text { Metrics: } \\
\text { - Satisfaction with attention to new } \\
\text { requirements. }\end{array}$ \\
\hline INTERNAL & LEARNING AND GROWTH \\
\hline $\begin{array}{l}\text { Objective: Delivery of programs on } \\
\text { time, within budget, complying } \\
\text { with quality requirements and } \\
\text { standards. } \\
\text { Metrics: } \\
\text { - Project execution. } \\
\text { - Quality compliance of the } \\
\text { projects. }\end{array}$ & $\begin{array}{l}\text { Objective: Competent and } \\
\text { motivated staff with mutual } \\
\text { understanding of technology and } \\
\text { business. } \\
\text { Metrics: } \\
\text { - IT Business Training. } \\
\text { - Business IT Training. } \\
\text { Objective: Knowledge, experience } \\
\text { and initiatives for business } \\
\text { innovation. } \\
\text { Metrics: } \\
\text { - Understanding of the possibilities } \\
\text { of technological innovation of } \\
\text { authorities. } \\
\text { - Approved IT initiatives. }\end{array}$ \\
\hline
\end{tabular}

IT processes. Based on the IT operation model established for the University of Cuenca, the 40 critical objectives prioritized in the criticality assessment of governance and management objectives were mapped (Figure 2). This set the objectives to be met in each of the elements of the IT governance model.

A guide was developed for the implementation of the IT Governance Model at the University of Cuenca to guide the implementation of the model. This guide takes into account all the components and prioritization criteria of the IT governance model, and are detailed in the processes to be implemented on a 4-year program.

The following components are included for each process:

Process Diagram. It is a graph of the activities required to generate an IT product or service.

Process characterization. It describes in detail the elements that make up the process, among which are: name, code, purpose, scope, suppliers, inputs, activities, managers, products or services that it delivers, and resources necessary for its execution.

Tasks. It details the tasks that make up the process.

Policies. They define the elements that govern processes based on internal and external strategic guidelines.

Performance indicators. They include measures to ensure that the objectives of the process are achieved.

Risks and controls. They describe the risks that may affect the performance, the delivery of the service or product, and the actions for its control.

\section{RELEVANT ASPECTS}

There are several aspects that are relevant to the implementation of this work. The IT Governance Model arises from a need or problem existing at the University of Cuenca, which is confirmed in the diagnostic phase and will be the basis for the prioritization and definition of components included in the proposed model. The criticality analysis of the objectives of government and management allowed to define that the institution was looking for the innovation/differentiation and efficiency of its services as a priority strategy; this would set the path for the definition of the IT governance framework. For the analysis of gaps in the objectives of governance and management, the suggested level was considered, which was not always the highest level but the level at which the organization wanted to reach; this prioritized the objectives and identified those that should guide future work in the governance and management of IT in the university.

On the other hand, the IT Governance Model also caused an important change in the organizational structure of the university's IT Directorates (DTICs). Two governing committees were established: Strategic Committee (CETI) and Management Committee (CGTI), and five units to manage innovation, architecture, projects, quality and security activities in a cross-cutting way, involving the development, operation and delivery of services to the university community.

Finally, progress cannot be validated if it is not measured. To do this, the IT Balanced Scorecard that includes the Governance Model is relevant, as it allows to measure the benefits that IT provides to the organization, controlling and checking the value that IT brings to the university, which is the main goal for the implementation of an IT governance model.

\section{LESSONS LEARNED}

There are several lessons learned that stand out in the development of this work:

1. Implementing an IT Governance Model for a university is essential to ensure that IT and IT investments add value to the organization.

2. Implementing an IT Governance Model is not difficult to achieve; there are methodologies, best practices and 
standards that guide activities to achieve it.

3. The participation of IT service users (teachers, employees, students) and IT staff, as well as environment analysis is momentous in identifying and prioritizing governance objectives, which are the basis for the implementation of the governance model.

4. It is very important to be willing to recognize problems, to change and to consider the vision of the authorities and the $\mathrm{CIO}$ of the university to achieve an adequate definition of the IT governance model to be implemented.

\section{CONCLUSIONS AND FUTURE STUDIES}

The defined IT Governance Model has meant a strong change in the way the development of activities at the University of Cuenca is conducted. The creation of the Strategic Committee on Information Technologies (CETI) leads to the direct participation of the university's directives in the management of the decisions to be made regarding the development of IT in the institution. On the other hand, the IT director, as part of the strategic committee, becomes a key player in decisions about the incorporation of IT into the organizational strategy and the generation of value for the institution.

The re-structure of the IT Directorate and its functions and the creation of the IT Management Committee (CGTI) enable adequate coordination of activities, undermining unnecessary complexity and rigidity of processes. Similarly, the performance indicators included in the IT Balanced Scorecard quantify the level of IT contribution to the organization.

To ensure that this governance framework is sustainable in the time and fulfills the purpose for which it has been created, it is planned to carry out the following future work:

1. To develop a statistical evaluation regarding the results of the implementation of the new governance and IT management model at the University of Cuenca.

2. To promote the creation of an IT governance culture in Ecuadorian and Latin American universities, and to generate collaboration processes that accelerate the improvement of the system.

3. To develop an IT Governance Model for Latin American universities that takes into account global standards and best practices, but at the same time that would adapt to the characteristics of Latin American university culture.

\section{REFERENCES}

[1] Laudon, Kennet C. \& Laudon, Jane P., (2018) Management Information Systems, 15th Edition, Prentice Hall, (2018).

[2] COBIT 2019 Framework: Governance and Management Objectives, ISACA, (2019).

[3] ISO/IEC 38500:2015 INFORMATION TECHNOLOGY GOVERNANCE OF IT FOR THE ORGANIZATION

[4] Val IT Framework for Business Technology Management, ISACA, (2013)
[5] Chinkes E., Tam J., Padilla R., Valdivia F., Vargas R., Price R., Holguín A., Rey J., Musse J., (2018) Las Tecnologías de la Información y la Comunicación: Potenciando la Universidad del Siglo XXI, Primera Edición, RedCLARA, (2015).

[6] Cordero D., Mejores Prácticas para Implantar el Gobierno de Tecnologías de la Información en la Universidad Ecuatoriana, (2015).

[7] Gómez C. Aguilar L. Velazco S., Principios de gobierno de tecnologías de información en las universidades de Colombia, COMTEL, (2013).

[8] Cadena S., Córdova J., Enríquez R. Llorens F., Padilla R. Estado de las Tecnologías de Información y Comunicación en las universidades ecuatorianas (UETIC 2019).

[9] Fernández A., Llorens F, Gobierno de TI para universidades, CRUE, (2011).

[10] Zambrano M. Molina-Sabando L., Diagnóstico situacional del gobierno de las Tecnologías de Información. Caso Universidad Laica Eloy Alfaro de Manabí, UNEMI, (2017).

[11] Estado actual de las tecnologías de la información y las comunicaciones en las instituciones de educación superior en México (Estudio 2018), ANUIES, (2018).

[12] Fernández A., Torres A., Díaz J., Resultados de un proyecto de arranque en la implementación del Gobierno de las Tecnologías de la Información en universidades de Colombia.

[13] Rada S., Tesis de Maestría sobre Marco de gobierno y gestión para arquitectura de TI en instituciones de educación superior en Colombia: caso de estudio Universidad del Magdalena, Fundación Universidad Del Norte, (2018).

[14] Quintanilla M., Modelo de referencia de gobierno de las tecnologías de la información para instituciones universitarias, (2016).

[15] Fernández A. Llorens-Largo F., Gobierno de las TI en las Universidades Españolas.

\section{ACKNOWLEDGMENT}

The authors thank the company HAWA Solutions for its collaboration in defining the IT Governance Model at the University of Cuenca. 